Greer, C. and Reiner, R. (2013) 'Labelling, Media, Crime and Justice', in Bruinsma, G. and Weisburd, D. (eds.) The Encyclopaedia of Criminology and Criminal Justice, New York: Springer Verlag.

\title{
Labelling, Deviance and Media
}

\author{
SYNONYMS: labelling theory, labelling perspective
}

\section{OVERVIEW}

Labelling theory is a perspective that emerged as a distinctive approach to criminology during the 1960s, and was a major seedbed of the radical and critical perspectives that became prominent in the 1970s. It represented the highpoint of an epistemological shift within the social sciences away from positivism - which had dominated criminological enquiry since the late-1800s - and toward an altogether more relativistic stance on the categories and concepts of crime and control. It inspired a huge amount of work throughout the 1960s and 1970s, and still resonates powerfully today. This short chapter maps out some of the ways in which labelling, deviance, media and justice interact at the levels of definition and process. It presents an overview and analysis of key mediatised labelling processes, such as the highly influential concept of moral panics. It discusses how the interconnections between labelling, crime and criminal justice are changing in a context of technological development, cultural change and media proliferation. The conclusion offers an assessment and evaluation of labelling theory's long-term impact on criminology.

\section{THE ROOTS OF THE LABELLING PERSPECTIVE}

The labelling perspective emerged at a time of radical intellectual change in the 1960s. The intellectual problem, as labelling theorists saw it, was that the study of crime had narrowed into two key questions: 1 ) why do they do it? and 2) how do we stop them from doing it? Government bodies and funding agencies reinforced the notion that 'they' were different from 'us', and that 'crime' was entirely distinct from 'criminal justice'. Such thinking had laid foundations for the resurgence of a separate academic discipline of 'positivist criminology', which functioned as policy science of crime, the criminal and crime control. There was an assumed consensus over what constituted crime, and the operations of criminal justice were seen as of interest only in terms of making them more effective in controlling crime. Yet nobody appeared to be asking why some behaviours were deemed criminal in certain contexts, while others were not. And why some people were deemed deviant and in need of correction or punishment, whilst others - who engaged in similar behaviours - were not. 
Though Durkheim had discussed the problematic definition of crime in the late $19^{\text {th }}$ century (Durkheim 1895/1964: 69-72), and scholars such as Frank Tannenbaum, George Herbert Mead and W. I. Thomas had been writing more or less directly about labelling processes since the 1930s, it is Howard Becker's (1963) Outsiders: Studies in the Sociology of Deviance that has become the best known and most influential statement of labelling theory. Building on the theoretical foundations of social constructionism and symbolic interactionism, Becker sought to problematise systematically precisely those questions that mainstream 'correctionalist' criminology left unexplored. He argued (1963: 14), 'The same behaviour may be an infraction of the rules at one time and not at another; may be an infraction when committed by one person, but not when committed by another; some rules are broken with impunity, others are not. In short, whether a given activity is deviant or not depends in part on the nature of the act (that is whether or not it violates some rule) and in part on what other people do about it'.

Understanding the highly selective nature of labelling, the equally selective nature of the social reaction to which it may or may not give rise, and the consequences for those who are labelled, required analysing complex and contested power relations as both microinteractional and macro-social processes. For Edwin Schur (1979: 160, italics in original) , the labelling perspective is thus concerned with both 'definition and process at all the levels that are involved in the production of deviant situations and outcomes. Thus, the perspective is concerned not only with what happens to specific individuals when they are branded as deviant ('labeling' in the narrow sense) but also with the wider domains and processes of social definitions and collective rule-making that frequently lie behind such concrete applications of negative labels'.

Key questions for labelling theorists therefore include: How are labels created or socially constructed? How are labels imposed? How and why do particular behaviours become defined as 'normal' or 'deviant'? What enables labellers to impose their particular definitions upon behaviours, actions and situations? How does the labelling process work and with what consequences?

\section{KEY ISSUES/CONTROVERSIES}

\section{Labelling, Media and Crime}

The mass media play at least a subordinate role in all the major theoretical perspectives attempting to understand crime and criminal justice. To illustrate this, the predominant theories of crime can be assembled in a simple model. For a crime to occur there are five logically necessary preconditions, which can be identified as: labelling; motive; means; opportunity; and the absence of controls (Reiner 2007: 80-90). The media potentially play a 
part in each of these elements, and thus can affect levels of crime in a variety of ways (Greer and Reiner 2012: 256-61).

\section{Labelling}

For an act to be 'criminal' (as distinct from harmful, immoral, anti-social, etc.) it has to be labelled as such. This involves the creation of a legal category. It also requires the perception of the act as criminal by citizens and/or law enforcement officers if it is to be recorded as a crime. The media are an important factor in both processes, helping to shape the conceptual boundaries and recorded volume of crime.

The role of the media in helping to develop new (and erode old) categories of crime has been emphasized in most of the classic studies of shifting boundaries of criminal law within the 'labelling' tradition. Becker's (1963) seminal book Outsiders analysed the emergence of the Marijuana Tax Act in the USA in 1937, emphasizing the use of the media as a tool of the Federal Bureau of Narcotics and its moral entrepreneurship in creating the new statute. Since this pioneering work many studies have illustrated the crucial role of the media in shaping the boundaries of deviance and criminality, by creating new categories of offence, or changing perceptions and sensitivities, leading to fluctuations in apparent crime (Young, 1971, Cohen, 1972, Hall et al, 1978). For example, Roger Graef's celebrated 1982 fly-on-thewall documentary about the Thames Valley Police was a key impetus to reform of police treatment of rape victims (Greer and Reiner 2012: 256). This also contributed, however, to a rise in the proportion of victims reporting rape, and thus an increase in the recorded rate. Many other studies document media-amplified 'crime waves' and 'moral panics' about law and order (Goode and Ben-Yehuda 2009 ).

What all these studies illustrate is the significant contribution of the media to determining the apparent level of crime. Increases and (perhaps more rarely) decreases in recorded crime levels are often due in part to the deviance construction and amplifying activities of the media .

\section{Motive}

A crime will not occur unless there is someone who is tempted, driven, or otherwise motivated to carry out the 'labelled' act. The media feature in many of the most commonly offered social and psychological theories of the formation of criminal dispositions. Probably the most influential sociological theory of how criminal motives are formed is Merton's version of anomie theory (Merton 1938/1957), echoes of which are found in more recent work (See Special Issue of Theoretical Criminology 11/1 2007; Reiner 2007: 14-5, 84-5). The media play a key role in these accounts of the formation of anomic strain generating 
pressures to offend. The media are pivotal in presenting for universal emulation images of affluent life-styles, which accentuate relative deprivation and generate pressures to acquire ever higher levels of material success regardless of the legitimacy of the means used.

Psychological theories of the formation of motives to commit offences also often feature media effects as part of the process (Greer and Reiner 2012: 247-62). It has been claimed that the images of crime and violence presented by the media are a form of social learning, and may encourage crime by imitation or arousal effects. Others have argued that the media tend to erode internalized controls by disinhibition or desensitization through witnessing repeated representations of deviance ().

\section{Means}

It has often been alleged that the media act as an open university of crime, spreading knowledge of criminal techniques. This is often claimed in relation to particular causes célèbres or horrific crimes, for example during the 1950s' campaign against crime and horror comics. A notorious case was the allegation that the murderers of Jamie Bulger had been influenced by the video Child's Play 3 in the manner in which they killed the unfortunate toddler. A related line of argument is the 'copycat' theory of crime and rioting. Despite a plethora of research and discussion, the evidence that this is a major source of crime remains weak.

\section{Opportunity}

The media may increase opportunities to commit offences by contributing to the development of a consumerist ethos, in which the availability of tempting targets of theft proliferates. The domestic hardware and software of mass media use-TVs, videos, radios, $\mathrm{CDs}$, personal computers, mobile phones-are the common currency of routine property crime, and their proliferation has been an important aspect of the spread of criminal opportunities.

\section{Absence of controls}

Motivated potential offenders, with the means and opportunities to commit offences, may still not carry out these crimes if effective social controls are in place. These might be external-the deterrent threat of sanctions represented in the first place by media made criminality the police- or internal- the still, small voice of conscience-what Eysenck has called the 'inner policeman'. 
A regularly recurring theme of respectable anxieties about the criminogenic consequences of media images of crime is that they erode the efficacy of both external and internal controls. They may undermine external controls by derogatory representations of criminal justice, for example ridiculing its agents, a key complaint at least since the days of Dogbery, resuscitated in this century by the popularity of comic images of the police, from the Keystone Cops onwards. Serious representations of criminal justice might undermine its legitimacy by becoming more critical, questioning, for example, the integrity and fairness, or the efficiency and effectiveness of the police. Negative representations of criminal justice could lessen public cooperation with the system, or potential offenders' perception of the probability of sanctions, with the consequence of increasing crime.

Probably the most frequently suggested line of causation between media representations and criminal behaviour is the allegation that the media undermine internalized controls, by regularly presenting sympathetic or glamorous images of offending. In academic form this is found in the psychological theories about disinhibition and desensitization, which were referred to in the section above on the formation of motives. In sum, there are several possible links between media representations of crime and criminal behaviour which are theoretically possible, and frequently suggested in criminological literature and political debate. In the next section I will review some of the research evidence examining whether such a link can be demonstrated empirically.

\section{Labelling, Media and Moral Panics}

The successful labelling of a particular situation or set of conditions as deviant and in need of amelioration can, in the extreme, result in 'moral panic'. The term was first used by Young (1971) in his study of subcultures and drugtaking. Cohen (1972) developed and extended the concept in his analysis of the sensationalistic, heavy-handed and ultimately 'disproportionate' reaction to the Mods and Rockers disturbances in an English seaside resort in 1964. Though the damage was in financial terms minor, Cohen traces the spiralling social reaction through initial intolerance, media stereotyping, moral outrage, increased surveillance, labelling and marginalisation, and deviancy amplification leading to further disturbances that seemed to justify the initial concerns. The flamboyant misbehaviour of youth subcultures, independent and sexually and economically liberated, affronted the post-War values of hard work, sobriety and deferred gratification. At a time of rapid social change, they were a visible index of a world that was slipping away - 'folk devils' who provided a crystallising focus for social anxiety and 'respectable fears'. Cohen used the building blocks of labelling theory - social constructionism, symbolic interactionism, deviancy amplification, social psychology - but also incorporated the lesser known academic literature on 'disaster research' to describe the various phases of a moral panic warning, impact, inventory, reaction - and chart its progression. 
Hall et al. (1978) politicised the concept by locating it within a broader political economy perspective in their analysis of a 'mugging' moral panic which, they argued, was constructed to address an escalating crisis in state hegemony. Drawing from an eclectic mix of influences, their account connects 'new deviancy theory, news media studies and research on urban race relations with political economy, state theory and notions of ideological consent' (Mclaughlin, 2008: 146). For some critical criminologists, it represents the high point of Marxist theorising about crime, law and order and the state. Whilst fully acknowledging the sophistication of this work, Cohen (2011) has nonetheless noted a wider tendency to over-politicise the concept at the expense of its sociological meaning and application. Hall (2007) has suggested in response that politicisation was a necessary developmental stage, and that the full explanatory potential of the moral panic concept was, in fact, only realised through its construction as ideology.

Goode and Ben-Yehuda (2009) developed Cohen's discussion of moral panic by paying particular attention to the criteria that should be in place before it can be suggested that a 'moral panic' is occurring. They identify five key features of the phenomenon: (i) concern (a reported condition or event generates anxiety); (ii) hostility (the condition or event is condemned and, where there are clearly identifiable individuals who can be blamed, these are labelled as 'folk devils'); (iii) consensus (the negative social reaction is widespread and collective); (iv) disproportionality (the extent of the problem and the threat is poses are exaggerated); ( $v$ ) volatility (media attention and the associated panic emerge suddenly and with intensity, but can dissipate quickly too). Media are central to all of these.

'Moral panic' is one of the most widely used terms in the sociological analysis of crime and justice, and has transcended academic discourses to become commonplace in political rhetoric and popular conversation (Altheide, 2009). Given its prolific usage, it is surprising that few commentators have subjected the concept to sustained and rigorous critical investigation. With the split in the criminological left in the late-1970s, the concept was dismissed by Left Realists as 'left idealism', and accused of obfuscating the painful 'realities' of criminal victimisation by propagating the view that 'the crime problem' is socially constructed (Young, 1979). In exploring the anatomy of the concept, critics have queried the notions of 'disproportionality' and 'volatility': the first, since this assumes a superior knowledge of the objective reality of the issue against which the reaction is measured, and a corresponding assumption of what a 'proportionate' reaction would look like. The second, because in a contemporary multi-media world characterised by ontological insecurity and state of a permanent free-floating anxieties, the notion of discreet, self-contained, volatile moral panics may need some rethinking (McRobbie and Thornton, 1995). Cohen has responded to all of these criticisms. But such critical interventions, both from within and outside of criminology, have barely interrupted the general tendency to arbitrarily apply the concept to explain everything from global warning to 'Swine Flu'. The broadly uncritical application of the moral panic concept has led Garland (2008) to reassert two elements of the original analysis, which are absent from many contemporary studies: (i) the moral 
dimension of the social reaction - most issues can be moralised, but many are not in and of themselves 'moral', and cannot automatically be analysed as such; and (ii) the idea that the deviant conduct in question is somehow symptomatic of a wider problem - a threat to established values, or a particular way of life. Struggles over the power to label and to label effectively via media discourses, of course, remain fundamental to the moralisation of particularly 'social problems', the identification of folk devils, the persuasive representation of threats to particular forms of social existence, and the prescription of ameliorative action.

\section{Labelling and Trial by Media}

Another way in which the news media are directly involved in labelling is the phenomenon of 'trial by media' (Greer and McLaughlin 2011, 2013). 'Trial by media' can be defined as a dynamic, impact-driven, news media-led process by which individuals - who may or may not be publicly known - are tried and sentenced in the 'court of public opinion'. The targets and processes of 'trial by media' can be diverse, and may range from pre-judging the outcome of formal criminal proceedings against 'unknowns' to the relentless pursuit of high-profile celebrity personalities and public figures deemed to have offended in some way against an assumed common morality.

Despite their clear diversity, such 'trials' share certain core characteristics. In each case, the news media behave as a proxy for 'public opinion' and seek to exercise parallel functions of 'justice' to fulfil a role perceived to lie beyond the interests or capabilities of formal institutional authority. Due process and journalistic objectivity can give way to sensationalist, moralising speculation about the actions and motives of those who stand accused in the news media spotlight. Judicial scrutiny of 'hard evidence' yields ground to 'real time' dissemination of disclosures from paid informants and hearsay and conjecture from 'well placed sources'. Since the news media substitute for the prosecution, judge and jury, the target may find themselves rendered defenceless. The default position is 'guilty until proven innocent'. Those found 'guilty' will be subjected to righteous 'naming and shaming' followed by carnivalesque condemnation and ridicule. The public appeal of 'trial by media' is evidenced by increased circulation and web traffic. And by no means is it restricted to the British press.

Thus, in recent years police commissioners, senior politicians, banking executives and, in the UK, the entire political establishment, as well as countless members of the public who are suspected of, but not yet charged with, any range of alleged criminal activities, have been subjected to mediatised scandal and trial by media (Greer and Mclaughlin 2010, 2011, 2012, 2013). The results of such high-profile labelling and public shaming, depending on the target, can range from deep and lasting reputational damage, public apologies, high-level resignations, radical political reform or criminal proceedings. 


\section{Labelling, Media and Criminal Justice}

Powerful organisations and institutions tend to hold a distinct advantage in defining the nature of reality as represented via news media. Despite considerable variation in theoretical and methodological approach, decades of research has confirmed that the institutionally powerful enjoy privileged positions as 'primary definers' at the top of the 'hierarchy of credibility', and that a pro-establishment perspective is structurally and culturally advantaged, if not necessarily guaranteed in news media representations (Ericson, et al. 1991; Hall, et al. 1978). Historically, then, the power to label has tended to rest more or less firmly in the hands of those who command institutional authority. There is good evidence to suggest, however, that with the proliferation and diversification of media in recent decades, the power of institutional authority to effectively 'define how things are' and set the terms of public debate, is becoming increasingly contested and unstable.

In a digital multi-media age, a proliferation of news platforms, sites and formats has been paralleled by a rapidly expanding array of news sources and producers of content, leading to the creation of an unprecedented amount of potentially newsworthy information, and a remarkable number of 'news spaces' in which to broadcast/publish it. In the process, increasingly sophisticated, interactive news audiences are reconstituted as consumers once content to be told what the news is, now increasingly interested in being part of the production process. Armed with cellphones, Blackberries or iPhones, all citizens are potential 'citizen journalists'. A photo can be taken on a mobile phone, tweeted on Twitter.com, picked up by other users, and disseminated like a virus online. Internet monitoring by mainstream news media outlets means that dramatic amateur photographic, audio or video content can become headline news. Citizen journalism has been instrumental not only in providing newsworthy images, but also in defining the news itself - in shaping representations of key global events. From the police brutality against Rodney King filmed by camcorder in Los Angeles in 1991, to the 7/7 London bombings of 2005, to Hurricane Katrina, street protests in Tehran, and the Haiti earthquake, many of the defining images that now form a key part of the 'official record' of events were taken with hand-held recording devices and posted on social media sites. The emergence of the citizen journalist carries significant implications for official institutions that would seek to control the representing of crime and justice in the news. This phenomenon has been seen as a significant modification of existing power relations, offering what has been called 'synopticon' (Mathiesen 1997), providing the mass of the population with some potential to record elite deviance.

The police can no longer simply 'deny out of existence' incidents of police violence in public protest situations, since these are ever-more likely to be captured on camera and broadcast to the world (Greer and Mclaughlin 2010, 2012). The same can be said of governments that would engage in larger scale abuses of their people and seek to conceal this from 
international scrutiny. And politicians or public officials, who may previously have fiddled expenses, taken bribes, engaged in illicit affairs when they should have been attending to the affairs of state, have all become more 'visible' and, thus, more vulnerable to public exposure, labelling, trial by media, and mediatised justice.

The democratisation of public involvement with the news production process, and the 'new visibility' (Thompson, 2005) to which institutional and state authority are continually subjected, are altering the dynamics of 'communication power' that shape our constructed realities. Of course, citizen journalists are neither automatically nor naturally imbued with cultural or official authority: they are not 'authorised knowers', who command access to mainstream news media 'as of right'. Their position in the 'hierarchy of credibility' is entirely precarious and contingent. Media access is not granted because of who citizen journalists are, but rather because of where they are and what they have. Their credibility and authenticity as news sources derives from their capacity to provide 'factual' visual evidence of 'live events' which, in a multi-platform news media market, constitutes an important and cost-effective resource for 'making news'. Nevertheless, citizens are becoming increasingly involved in the processes of public labelling and social construction that determine what, and who, is defined as honest or corrupt, competent or incompetent, legitimate and illegitimate, compliant or deviant. As such, they are centrally involved in the reconfiguration of notions of 'crime' and 'justice' in multi-media worlds.

\section{Labelling Theory: Evaluation and Critique}

The labelling perspective has transformed criminological theory and practice since the 1960s. It has made many permanently valuable contributions, above all the recognition of criminal law and justice as problematic research areas, that shape at least as much as they control crime. Criminology conferences and textbooks today devote as much attention to research on and analysis of criminal justice, from a non-correctionalist standpoint, as they do to the study of offending, a legacy (albeit often unrecognised) of labelling theory. The two sub-fields that the authors of this chapter have spent most of their careers researching (policing, and media representations of crime/criminal justice) were almost entirely absent from criminologists' agendas until the 1960s, and the questions raised then by labelling theorists. The problematic character of crime statistics, now universally recognised, is another contribution of labelling theorists. These impacts reflect the labelling perspective, but its influence is largely unacknowledged, and the developments have come to be taken for granted and domesticated within mainstream criminology.

What is more questionable is the imperialistic version of labelling theory that was trumpeted in its heyday, and made large claims about itself as offering a total theory of crime. This grandiose version of labelling theory originated and flourished as the criminology 
of the 1960 s counter-culture, and could only be plausible as a general theory in that context.

The imperialistic version claimed that concepts of crime were entirely relative and dependent on perceptions and labelling. It further suggested that labelling and social reaction were the principal explanations of crime and deviance. These claims are epitomised by two frequently cited quotes from key architects of the perspective. The relativity assertion is captured by Becker's statement that 'deviance is not a quality of the act... but of the application... of rules and sanctions' (Becker 1963). The explanatory power of labelling is asserted most explicitly by Lemert: 'Older sociology tended to rest heavily upon the idea that deviance leads to social control... (T)he reverse idea i.e. that social control leads to deviance, is equally tenable and the potentially richer premise for studying deviance in modern society' (Lemert 1967).

Both claims have some validity, but the exaggerated imperialistic versions, postulated by Becker, Lemert and others, were neither new, nor true without considerable qualification. Criminology before labelling theory (and indeed even nowadays) often took the concept of crime for granted. But its problematic character had already been emphasised by Durkheim and others. Seeing the making and enforcement of criminal law as a part of criminology was indeed acknowledged by some criminologists long before the labelling revolution. Moreover it was assumed by criminal lawyers, both in textbooks and judicial decisions (Proprietary Articles Trade Assn. v. Alt. Gen. for Canada [ 1931 ] AC at 32, per Lord Atkin). Legal scholars had studied the emergence and change of criminal laws long before the advent of labelling theory (e.g. Hall 1935/1952). Recognising the historical and social diversity of what precisely is criminalised at different times and places (Reiner 2007: Chap.2; Lacey and Zedner 2012) does not entail complete relativity. As Hart suggested persuasively, there seems to be a 'minimum content of natural law', activities that are regulated in all societies because they are conditions of viable social existence, even though the precise content and manner of proscription and sanctioning is variable (Hart 1961: Chapter IX, Part II).

The recognition of labelling as a cause of crime was also not entirely new, and had been anticipated even by some criminologists in the positivist tradition (most explicitly Wilkins 1964 , whose concept of deviance amplification in turn influenced labelling theorists). Whilst it is the case, as Lemert claims, that often 'social control leads to deviance' it is disputable whether it is the 'richer premise for studying deviance'. Lemert's claim rests on the assumption that 'secondary deviance', which follows labelling, is more pervasive and problematic than 'primary deviance', which precedes it. But this is an empirical question that is likely to vary in different times and places, and with regard to different kinds of deviance and social reaction, not a 'premise'.

Any plausibility the imperialistic claims of labelling theory had derived from the limited nature in practice of their empirical research. These tended to concentrate on marginal or exotic forms of deviance, which lend themselves to being seen as harmful or problematic 
not intrinsically but primarily if not solely because of labelling: marijuana use, the bohemian subculture of jazz musicians (Becker 1963); 'hustlers, beats and others' (Polsky, 1967); 'crimes without victims' (Schur, 1965). An early critique castigated this pithily as the 'sociology of nuts, sluts and "preverts" (sic)' (Liazos 1972).

The labelling theory pioneers' focus on the dramatic and colourful made it much easier to ignore the harms done by some primary deviance. They concentrated on the creation of crime by the labelling activities of low-level control agents, reversing the moral assessments of criminal law and justice - as explicitly advocated by Becker in his call for criminologists to ask 'Whose Side Are We On?' (1967). This not only neglected the harms done by some crime, but bracketed out its structural causes, and the structural determinants of control activity - law, culture, political economy, wider social patterns and institutions (as Gouldner argued in his 1968 repost to Becker 'The Sociologist As Partisan'). This critique stimulated the morphing of labelling theory into more politically radical forms of 'new criminology' and 'deviance theory' in the 1970s (the core classics were Cohen 1971; Taylor, Walton and Young 1973;; as well as the seminal studies discussed extensively in this paper, Young 1971; Cohen 1972; Hall et al 1978).

Labelling theory has had a huge impact, fundamentally shifting the criminological paradigm away from a taken for granted correctionalist stance, and stimulating a variety of forms of critical perspective. Much of its influence is now hidden, domesticated in the proliferating analyses of policing, media, and criminal justice. Although the sweeping claims of its originators are hard to sustain, its legacy lives on explicitly in contemporary cultural criminology and other qualitative and critical approaches.

RELATED ENTRIES : labelling: history and context; new media and crime images; police and social media;

\section{RECOMMENDED READING AND REFERENCES}

Altheide, D. 2009 'Moral Panic: From Sociological Concept to Public Discourse', Crime, Media, Culture: An International Journal 5(1): 79-99

Becker, H. (1967) 'Whose Side Are We On?' Social Problems, 14/1: 239-47.

Becker, H. S. 1963 Outsiders : studies in the sociology of deviance, London: Free Press of Glencoe. Cohen, S. (1971) ed. Images of Deviance London: Penguin.

Cohen, S. 1972 Folk devils and moral panics : the creation of the Mods and Rockers, London: MacGibbon and Kee.

Cohen, S. 2011 'Whose Side Were We On? The Undeclared Politics of Moral Panic Theory', Crime Media Culture: An International Journal 7(3): 28-38.

Durkheim, E. (1895/1964) The Rules of Sociological Method Glencoe: Free Press.

Ericson, R. V., Baranek, P. M. and Chan, J. B. L. 1991 Representing order : crime, law, and justice in the news media, Toronto: University of Toronto Press. 
Garland, D. 2008 'On the Concept of Moral Panic', Crime Media Culture: An International Journal 4(1): 9-30.

Goode, E. and Ben-Yehuda, N. 2009 Moral panics : the social construction of deviance, 2nd Edition, Chichester, West Sussex, U.K. ; Malden, Mass.: Wiley-Blackwell.

Gouldner, A. (1968) 'The Sociologist as Partisan: Sociology and the Welfare State' The American Sociologist 3(2): 103-116.

Greer, C. and Mclaughlin, E. 2012 'Media Justice: Madeleine McCann, Intermediatisation and' Trial by Media', in the British Press', Theoretical Criminology 16(4): 395-416.

Greer, C. and Mclaughlin, E. 2012 'This is not Justice': Ian Tomlinson, Institutional Failure and the Press Politics of Outrage', British Journal of Criminology, 52(2): 274-293.

Greer, C. and Mclaughlin, E. 2011 'Trial by Media: Policing, the News 24-7 News Mediasphere, and the Politics of Outrage', Theoretical Criminology 15(1): 23-46.

Greer, C. and Mclaughlin, E. 2010 'We Predict a Riot? Public Order Policing, New Media Environments and the Rise of the Citizen Journalist ', British Journal of Criminology 50(6): 1041-1059.

Greer, C. and Reiner, R. (2012) 'Mediated Mayhem: Media, Crime, Criminal Justice' in M.Maguire, R.Morgan and R.Reiner (eds.) The Oxford Handbook of Criminology, $5^{\text {th }}$.ed. Oxford: Oxford University Press.

Hall, J. (1935) Theft, Law and Society Indianopolis: Bobbs Merrill.

Hall, S. 2007 'Moral Panics: Then and Now' Moral Panics: Then and Now, British Academy.

Hall, S., Critcher, C., Jefferson, T., Clarke, J. and Roberts, B. 1978 Policing the crisis : mugging, the state, and law and order, London: Macmillan.

Hart, H. (1961) The Concept of Law Oxford: Oxford University Press.

Lacey, N. and Zedner, L. (2012) 'Legal Constructions of Crime' in M.Maguire, R.Morgan and R.Reiner (eds.) The Oxford Handbook of Criminology $5^{\text {th }}$ ed. Oxford: Oxford University Press.

Lemert, E. (1967) Human Deviance Englewood Cliffs: Prentice Hall.

Liazos, A. (1972) 'The Poverty of the Sociology of Deviance: Nuts, Sluts, and Preverts' Social Problems 20/1: 103-120.

Mathiesen, T. (1997) 'The Viewer Society: Michel Foucault's "Panopticon" Revisited' Theoretical Criminology $1 / 2:$ : 215-234.

McRobbie, A. and Thornton, S. 1995 'Rethinking “Moral Panic" for Multi-Mediated Social Worlds', British Journal of Sociology 46(4): 559-574.

Merton, R. 1938/1957 'Social Structure and Anomie', American Sociological Review 3: 672-682.

Polsky, N. (1967) Hustlers, Beats and Others London: Penguin.

Reiner, R. (2007) Law and Order: An Honest Citizen's Guide to Crime and Control Cambridge: Polity.

Schur, E. (1965) Crimes Without Victims Englewood Cliffs: Prentice Hall.

Taylor, I., Walton, P. and Young, J. (1973) The New Criminology London: Routledge.

Thompson, J. B. 2005 'The New Visibility', Theory, Culture \& Society 22(6): 31-51.

Young, J. 1971 The drugtakers : the social meaning of drug use, London: Paladin.

Young, J. 1979 'Left Idealism, Reformism and Beyond: from the New Criminology to Marxism', in F. Bob, R. Kinsey, J. Lea, S. Picciotto and J. Young (eds) Capitalism and the Rule of Law: from Deviancy to Marxism, London: Hutchinson. 